www.nature.com/pj

\title{
Synthesis of first- and second-generation imidazole- terminated POSS-core dendrimers and their pH responsive and coordination properties
}

\author{
Kensuke Naka, Shizuka Masuoka, Ryusuke Shinke and Maki Yamada \\ Imidazole-terminated first- and second-generation poly(amidoamine)-type oligomeric silsesquioxanes (POSS)-core dendrimers \\ (denoted as POSS-Im16 and POSS-Im32, respectively) were synthesized by the ester-amide exchange reaction from first- and \\ second-generation methyl ester-terminated POSS-core dendrimers, respectively. Transmittances of the aqueous POSS-Im32 \\ solution drastically decreased at $\mathrm{pH}>7.2$, but the change was reversible without hysteresis. The results of $\mathrm{pH}$ titrations \\ for POSS-Im16 and POSS-Im32 showed well-defined one-step titration curves identical to those of monomeric imidazole \\ compounds, such as 1-methylimidazole. Such simple acid-base behavior caused phase transition in the aqueous dendrimer \\ solution to be highly sensitive to $\mathrm{pH}$ changes. The $\mathrm{pKa}$ values of 1 -methylimidazole, POSS-Im16 and POSS-Im32 were 7.3, \\ 7.0 and 6.7, respectively. Spectrophotometric titrations of the aqueous dendrimer solutions with $\mathrm{Cu}^{2+}$ ions indicated that \\ coordination modes of POSS-Im16 changed from the $\mathrm{Cu}^{2+}-\mathrm{N}_{2} \mathrm{O}_{2}$ complex to the $\mathrm{Cu}^{2+}-\mathrm{N}_{4}$ complex as the concentration of the \\ dendrimers increased; however, only one complexation mode $\left(\mathrm{Cu}^{2+}-\mathrm{N}_{4}\right)$ existed between $\mathrm{Cu}^{2+}$ ions and POSS-Im32. \\ Polymer Journal (2012) 44, 353-359; doi:10.1038/pj.2011.145; published online 18 January 2012
}

Keywords: coordination; dendrimer; imidazole; $\mathrm{pH}$ responsive; POSS; silsesquioxane

\section{INTRODUCTION}

Using polyhedral oligomeric silsesquioxane (POSS) cores to synthesize dendrimers is attractive because it requires only a minimal number of synthetic steps; in addition, polyhedral structures of the POSS core can produce spherically symmetric dendrimers (even with earlier generations) more successfully than conventional cores can. ${ }^{1-4}$ These POSScored dendrimers have relatively globular conformations and fewer entangled branches, with a high proportion of terminal functional groups positioned on the external surfaces of the dendrimers, even in earlier generations. Morris and colleagues ${ }^{4,5}$ reported that these features were useful for the molecular carriers used as chemical catalysts to obtain the highest number of active sites possible; in these catalysts, the catalytic functionalities are tethered to the exterior surfaces of the dendrimers. Naka et al. ${ }^{6}$ synthesized a carboxylateterminated POSS-core dendrimer as the first anionic water-soluble dendrimer based on POSS; they also studied its complexation behavior with $\mathrm{Cu}^{2+}$ ions in an aqueous solution by spectroscopic methods and isothermal titration calorimetry. The conformation of the POSScore dendrimer causes a decrease in mobility of dendron chains and the sterically hindered structure on which $\mathrm{Cu}^{2+}$ ions are coordinated, even for early-generation dendrimers based on the rigid and symmetrical structure of the POSS core. The POSS-core dendrimer was more successful at entrapping guest molecules compared with a conventional dendrimer with the same terminal number. ${ }^{7}$ However, only a limited number of examples have been reported; no example has demonstrated the effect of generation numbers on the properties of POSS-core dendrimers.

In the field of dendrimer chemistry, the possibility of tailoring a dendrimer surface arranged with organic molecules that respond to stimuli such as light, solvent, heat and $\mathrm{pH}$ is particularly interesting. ${ }^{8-11}$ Kono and colleagues ${ }^{8}$ reported that the lower critical solution temperatures of the dendrimers decreased remarkably as the dendrimer solution increased from G3 to G5. Dendrimers terminated with functional groups have certain remarkable features that the conventional thermosensitive polymers do not, such as a three-dimensional structure and a precisely controlled molecule size. The ability to functionalize surface dendrimers to respond to stimuli has opened new avenues to use these materials in many applications. However, in the case of conventional dendrimers, high-generation dendrimers are required for sharp response to stimuli, because of the densely packed terminal groups. As POSS-core dendrimers are expected to produce spherically symmetric dendrimers in early generations without densely packed terminal groups, POSS-core dendrimers terminated with functional groups are expected to respond sharply to external stimuli. 
Terminal functional groups on POSS-core dendrimers are expected to show chemical behaviors similar to those of the corresponding monomeric molecules in solution because the terminal function groups are isolated; furthermore, they inhibit the movement of neighboring branches.

Imidazole rings have attracted much attention because of their metal ion binding and buffering properties in the physiological $\mathrm{pH}$ range. ${ }^{12}$ The imidazole ring is a major component of many biochemicals found in nature, such as histidine. Linear polymers grafted with imidazole units showed $\mathrm{pH}$-dependent phase transitions at a $\mathrm{pH}$ of $\sim 7.0 .{ }^{13,14}$ Here, we prepared first- and second-generation imidazoleterminated POSS-core poly(amidoamine)-type dendrimers. We demonstrated that the present POSS-core dendrimers show sharp phase transitions depending on $\mathrm{pH}$, even in an early generation and that the unique coordination behaviors of the metal ions depend on generation of dendrimers.

\section{EXPERIMENTAL PROCEDURE}

\section{Materials}

The first-generation methyl ester-terminated POSS-core poly(amidoamine)typed dendrimer (POSS-OMe16) prepared according to the literature ${ }^{1,2}$ was purified by size-exclusion chromatography (LH-20) using methanol as the eluent. Subsequently, the POSS-OMe16 dendrimer was reacted with excess ethylenediamine to produce the amino-terminated POSS-core dendrimer (POSS- $\left.\left(\mathrm{NH}_{3}\right) \mathbf{1 6}\right)$ according to the literature. ${ }^{1}$ All chemicals were purchased from Wako Pure Chemical Industries Ltd (Osaka, Japan).

\section{Measurements}

${ }^{1} \mathrm{H}-(300$ or $400 \mathrm{MHz}),{ }^{13} \mathrm{C}-(75$ and $100 \mathrm{MHz})$ and ${ }^{29} \mathrm{Si}-(100 \mathrm{MHz})$ nuclear magnetic resonance (NMR) spectra were recorded on a Bruker PDX-300 spectrometer (Bruker Biospin GmbH, Rheinstetten, Germany). The ultraviolet-vis spectra were recorded on a Jasco spectrophotometer (model V-670 KKN; Jasco, Tokyo, Japan). MALDI-TOF-MS (matrix assisted laser desorption ionization time-of-flight mass spectrometry) was recorded on a Bruker instrument (Autoflex II from Bruker Daltonics, Billerica, MA, USA). $\alpha$-Cyano-4hydroxycinnamic acid was used for MALDI matrices. Elemental analyses were performed on a Yanaco CHN analyzer (model CORDER MT-5; Yanaco, Tokyo, Japan)

\section{POSS-OMe32}

Methyl acrylate $(33.20 \mathrm{~g}, 0.386 \mathrm{~mol}$, 6 Equiv. against the primary amine) was added using a syringe to a solution of POSS- $\left(\mathbf{N H}_{3}\right) \mathbf{1 6}$ ( $\left.5.44 \mathrm{~g}, 2.01 \mathrm{mmol}\right)$, and the resulting mixture was heated for 6 days at $40^{\circ} \mathrm{C}$. After the volatiles were evaporated, a colorless oil of crude POSS-OMe32 remained. The crude product was purified by preparative size exclusion chromatography (LH-20) using methanol as the eluent to remove the unreacted products. The yield of pure POSS-OMe32 was $82 \%(8.40 \mathrm{~g}, 1.65 \mathrm{mmol}) .{ }^{1} \mathrm{H}-\mathrm{NMR}\left(\mathrm{CDCl}_{3}\right): \delta 3.66(\mathrm{~s}$, $48 \mathrm{H}), \delta 3.27(\mathrm{~m}, 32 \mathrm{H}), \delta 2.77(\mathrm{~m}, 96 \mathrm{H}), \delta 2.55(\mathrm{~m}, 48 \mathrm{H}), \delta 2.44(\mathrm{~m}, 64 \mathrm{H})$, $\delta 2.38(\mathrm{~m}, 32 \mathrm{H}), \delta 1.51(\mathrm{~s}, 16 \mathrm{H}), \delta 0.59(\mathrm{~s}, 16 \mathrm{H})$. MALDI-TOF-MS $(\mathrm{m} / \mathrm{z}$, $[\mathrm{M}+\mathrm{H}]^{+}$): 5463.78 (calculated for $\mathrm{C}_{232} \mathrm{~N}_{40} \mathrm{O}_{92} \mathrm{H}_{416} \mathrm{Si}_{8}$ ); 5464.23 (observed).

\section{POSS-Im16}

1-(3-Aminopropyl)imidazole $(2.13 \mathrm{~g}, 0.02 \mathrm{~mol})$ was added to POSS-OMe16 $(0.49 \mathrm{~g}, 0.22 \mathrm{mmol})$, and the resulting mixture was heated for 18 days at $30^{\circ} \mathrm{C}$ under nitrogen. The crude product was purified by preparative size exclusion chromatography (LH-20) using methanol as the eluent to remove the unreacted products. The yield of pure POSS-Im16 was $95 \%(0.78 \mathrm{~g}$, $0.21 \mathrm{mmol}) .{ }^{1} \mathrm{H}-\mathrm{NMR}\left(\mathrm{CDCl}_{3}\right): \delta 0.42(\mathrm{~s}, 16 \mathrm{H}), \delta 1.36(\mathrm{~s}, 16 \mathrm{H}), \delta 1.94(\mathrm{~s}$, $32 \mathrm{H}), \delta 2.31(\mathrm{~s}, 32 \mathrm{H}), \delta 2.65(\mathrm{~m}, 48 \mathrm{H}), \delta 3.13(\mathrm{~s}, 32 \mathrm{H}), \delta 4.00(\mathrm{~s}, 32 \mathrm{H}), \delta 6.95$ $(\mathrm{s}, 16 \mathrm{H}), \delta 6.99(\mathrm{~s}, 16 \mathrm{H}), \delta 7.52(\mathrm{~s}, 16 \mathrm{H}) .{ }^{13} \mathrm{C}-\mathrm{NMR}\left(\mathrm{CDCl}_{3}\right): \delta$ 9.497, 19.767, $30.920,33.812,36.173,44.468,49.841,55.480,119.164,129.135,137.269$, 172.984. ${ }^{29} \mathrm{Si}-\mathrm{NMR}: \delta 66.45$ (s). FT-IR $(\mathrm{KBr}): 1189\left(\mathrm{v}_{\mathrm{Si}-\mathrm{O}-\mathrm{Si}}\right)$. Anal. calcd for $\mathrm{C}_{168} \mathrm{~N}_{56} \mathrm{O}_{28} \mathrm{H}_{272} \mathrm{Si}_{8} 12 \mathrm{H}_{2} \mathrm{O}$ : C, 50.88; H, 7.22; N, 19.79. Found: C, 50.73; H,
7.35; N, 19.88. MALDI-TOF-MS $\left(m / z,[\mathrm{M}+\mathrm{H}]^{+}\right)$: 3786.176 (calcd for $\mathrm{C}_{168} \mathrm{~N}_{56} \mathrm{O}_{28} \mathrm{H}_{272} \mathrm{Si}_{8} 2 \mathrm{H}_{2} \mathrm{O}$ ); 3785.83 (observed).

\section{POSS-Im32}

1-(3-Aminopropyl)imidazole $(13.9 \mathrm{~g}, 0.111 \mathrm{~mol})$ was added to POSS-OMe32 (3.53 g, $0.694 \mathrm{mmol}$ ), and the resulting mixture was heated for 10 days at $50{ }^{\circ} \mathrm{C}$ under nitrogen. After the volatiles were evaporated, a colorless oil of crude POSS-Im32 remained. The crude product was purified by preparative size exclusion chromatography (LH-20) using methanol as the eluent to remove the unreacted products. The yield of pure POSS-Im32 was $80 \%(4.70 \mathrm{~g}$, $0.556 \mathrm{mmol}) .{ }^{1} \mathrm{H}-\mathrm{NMR}\left(\mathrm{CD}_{3} \mathrm{OD}\right): \delta 7.68(\mathrm{~s}, 32 \mathrm{H}), \delta 7.14(\mathrm{~s}, 32 \mathrm{H}), \delta 6.95$ $(\mathrm{s}, 32 \mathrm{H}), \delta 4.03(\mathrm{t}, 64 \mathrm{H}), \delta 3.23(\mathrm{~m}, 32 \mathrm{H}), \delta 3.15(\mathrm{~m}, 64 \mathrm{H}), \delta 2.77(\mathrm{~m}, 48 \mathrm{H})$, $\delta 2.77(\mathrm{~m}, 96 \mathrm{H}), \delta 1.94(\mathrm{~m}, 64 \mathrm{H}), \delta 1.55(\mathrm{~m}, 16 \mathrm{H}), \delta 0.62(\mathrm{~m}, 16 \mathrm{H}) .{ }^{13} \mathrm{C}-$ $\operatorname{NMR}\left(\mathrm{CDCl}_{3}\right): \delta 174.805,174.476,138.619,129.210,120.745,57.178,53.565$, 51.139, 49.836, 45.565, 38.677, 37.449, 34.762, 34.518, 32.021, 21.060, 10.712. ${ }^{29} \mathrm{Si}-\mathrm{NMR}: \quad \delta$ 66.30. FT-IR $(\mathrm{KBr}): 1189 \quad\left(\mathrm{v}_{\mathrm{Si}-\mathrm{O}-\mathrm{Si}}\right)$. Anal. calcd for $\mathrm{C}_{372} \mathrm{~N}_{124} \mathrm{O}_{64} \mathrm{H}_{612} \mathrm{Si}_{8} 18 \mathrm{H}_{2} \mathrm{O}$ (4 branches unreacted dendrimer): C, 53.22; $\mathrm{H}$, 7.56; N, 20.69. Found: C, 53.10; H, 7.72; N, 20.67. MALDI-TOF-MS $(\mathrm{m} / \mathrm{z}$, $[\mathrm{M}+\mathrm{H}]^{+}$): 8444.13 (calculated for $\mathrm{C}_{392} \mathrm{~N}_{136} \mathrm{O}_{60} \mathrm{H}_{640} \mathrm{Si}_{8}$ ); 8448.12 (observed).

\section{Potentiometric titration}

Potentiometric titrations were performed at room temperature using a $\mathrm{pH}$ meter (Horiba D-52, Horiba, Kyoto, Japan) and a glass electrode. Titrations were performed with $0.1 \mathrm{M} \mathrm{NaOH}$ in $2.0 \mathrm{M} \mathrm{NaCl}$ with constant number of imidazole units in the dendrimers. The $\mathrm{pH}$ of each aqueous solution of 1methylimodazole $(0.32 \mathrm{mmol})$, POSS-Im16 $(0.02 \mathrm{mmol})$ and POSS-Im32 $(0.01 \mathrm{mmol})$, which corresponds to $0.32 \mathrm{mmol}$ of imidazole in $60 \mathrm{ml}$ of distilled water with $2.0 \mathrm{M} \mathrm{NaCl}$, was adjusted to 3 with $0.5 \mathrm{M} \mathrm{HCl}$.

\section{Photometric determination}

Aqueous $\mathrm{CuSO}_{4}$ solutions were added to aqueous dendrimer solutions that ranged in concentration from 0.0025 to $0.2 \mathrm{~mm}$. The concentration of the $\mathrm{CuSO}_{4}$ solution was $0.2 \mathrm{~mm}$ for the POSS-Im16 solution and $0.1 \mathrm{~mm}$ for the POSS-Im32 solution. In the continuous variation experiment, mixed solutions were prepared such that the total reagent concentration of $\mathrm{Cu}^{2+}$ ions and dendrimers were maintained at $0.5 \mathrm{~mm}$.

\section{RESULTS AND DISCUSSION}

Synthesis of imidazole-terminated first- and second-generation POSS-core dendrimers

Imidazole-terminated first- and second-generation POSS-core dendrimers were synthesized with 1-(3-aminopropyl)imidazole from POSS-OMe16 and POSS-OMe32, respectively, by the ester-amide exchange reaction (Schemes 1 and 2). As silsesquioxane units are typically unstable in basic compounds, we examined the amidation condition of POSS-OMe16 with 1-(3-aminopropyl)imidazole by monitoring the presence of the methoxy group in ${ }^{1} \mathrm{H}$ NMR spectra (Figure 1). The rate of the ester-amide exchange reaction increased with increasing reaction temperature, and the silsesquioxane unit in POSS-Im16 decomposed at $40^{\circ} \mathrm{C}$ or above according to the ${ }^{1} \mathrm{H}$ NMR analysis. Thus, the reaction temperature should be $<40^{\circ} \mathrm{C}$ to prepare the dendrimer without decomposing the POSS core. However, no decomposition was observed at $70^{\circ} \mathrm{C}$ when using POSS-OMe32. These results suggest that increasing generation numbers inhibits decomposition by basic compounds because they can no longer attack the silsesquioxane core. After the solvent was removed under reduced pressure, both products were purified by preparative size exclusion chromatography to remove unreacted compounds.

The structures of POSS-Im16 and POSS-Im32 were identified based on multinuclear NMR data (Supplementary Figures S1-S6). The degrees of functionalization of dendrimers with the imidazole unit were estimated using ${ }^{1} \mathrm{H}$ NMR. The areas of the peaks of the aromatic protons on the imidazole ring were calculated and compared 


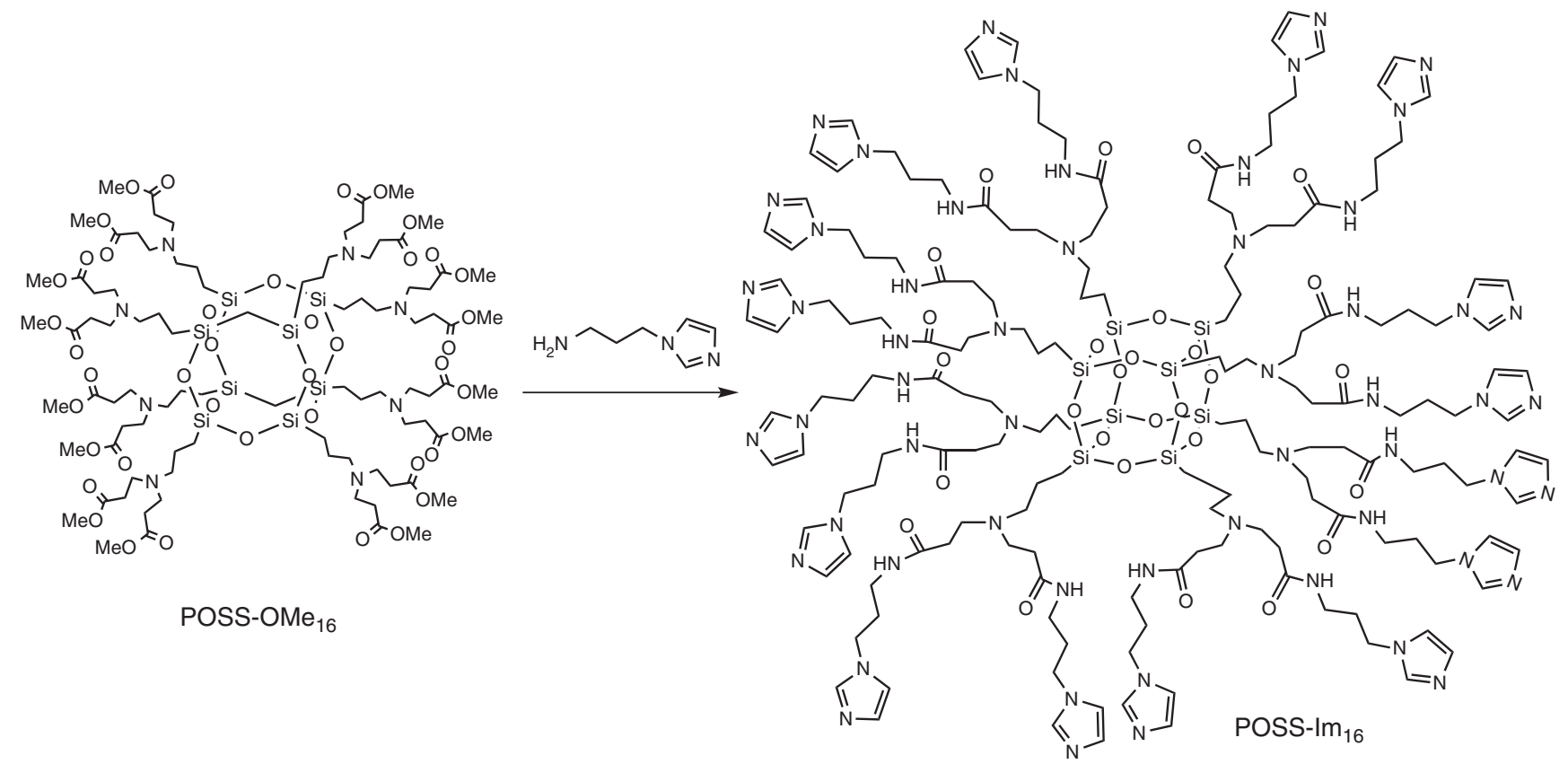

Scheme 1 Synthesis of POSS-Im16.

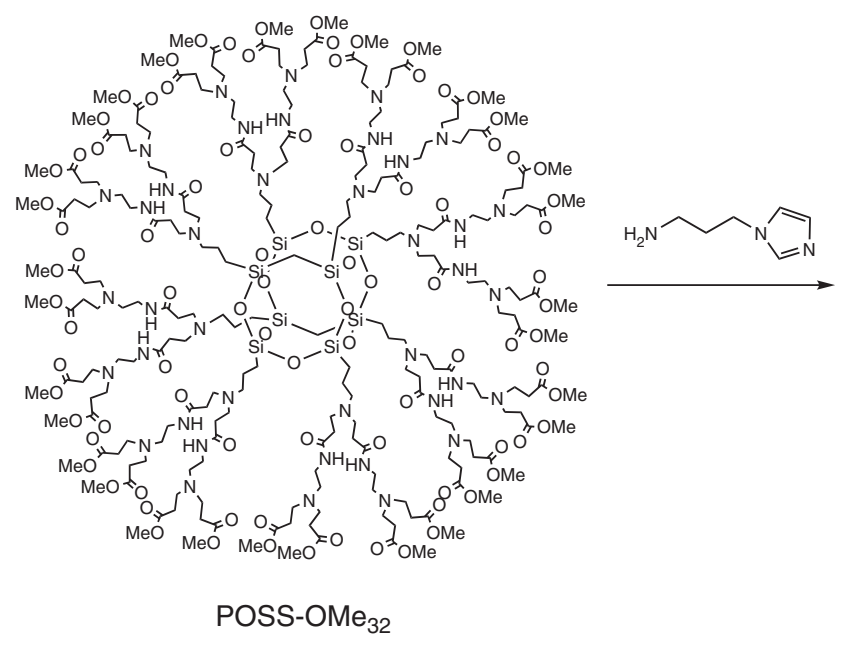

Scheme 2 Synthesis of POSS-Im32.

against values from the methylene protons on the POSS core and values from the remaining methoxy protons to determine the degrees of functionalization. Both dendrimers had high degrees of functionalization, which were 98 and 90\% for POSS-Im16 and POSS-Im32, respectively. The ${ }^{13} \mathrm{C}$ NMR spectra of both dendrimers confirmed their structures. In the ${ }^{29} \mathrm{Si}$ NMR spectra, peaks of the POSS units for POSS-Im16 and POSS-Im32 were observed at -66.45 and -66.30 p.p.m., respectively. No other peaks were detected, indicating that the POSS cores did not decompose.

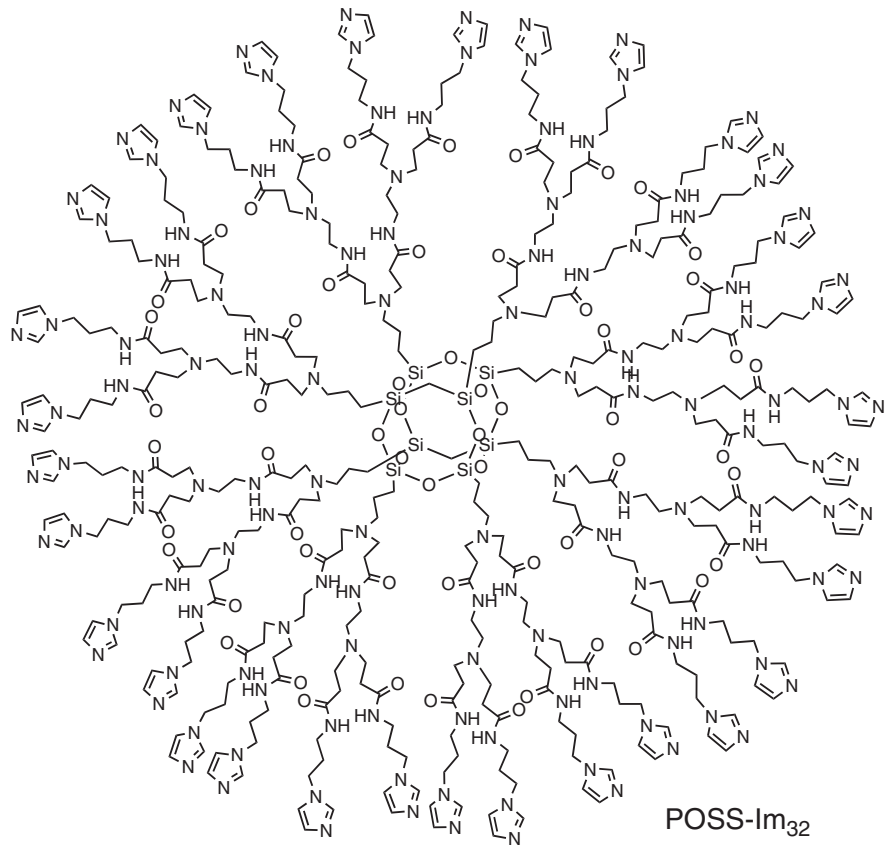

The MALDI-MS spectrum of POSS-Im16 showed the presence of 3 peaks at $3745.909,3766.081$ and $3785.83 \mathrm{~m} / z$, the first of which is very close to the molecular mass $\left(3749.136 \mathrm{~g} \mathrm{~mol}^{-1}\right)$ of the fully functionalized dendrimer (Supplementary Figure S7). The latter two molecular ion peaks are closed to the molecular mass of the dendrimers associated with one $\mathrm{H}_{2} \mathrm{O}$ molecule $\left(3767.152 \mathrm{~g} \mathrm{~mol}^{-1}\right)$ and two $\mathrm{H}_{2} \mathrm{O}$ molecules $\left(3785.168 \mathrm{~g} \mathrm{~mol}^{-1}\right.$ ). The elemental analysis of POSS-Im16 matched the fully functionalized dendrimer associated with $12 \mathrm{H}_{2} \mathrm{O}$ molecules. The MALDI-MS spectrum of POSS-Im32 contained a 

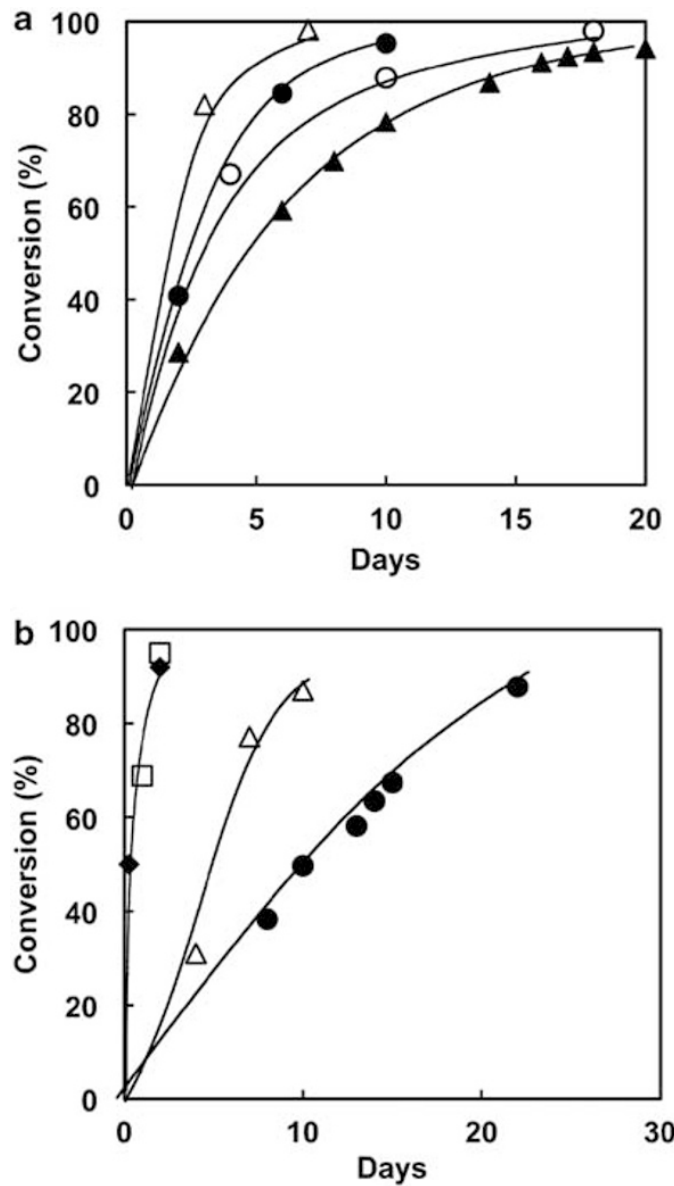

Figure 1 Time-dependent conversion of the methyl ester of (a) POSSOMe16 and (b) POSS-OMe32 with 1-(3-aminopropyl)imidazole at different reaction temperatures. (Panel a) $\boldsymbol{\Delta}: 25^{\circ} \mathrm{C}, \mathrm{O}: 30^{\circ} \mathrm{C}, \bullet: 40^{\circ} \mathrm{C}, \triangle: 50^{\circ} \mathrm{C}$. (Panel b) •: $40^{\circ} \mathrm{C}, \triangle: 50^{\circ} \mathrm{C}, \quad \square: 60^{\circ} \mathrm{C}, \bullet: 70^{\circ} \mathrm{C}$. POSS, poly(amidoamine)-type oligomeric silsesquioxane.

large number of signals (Supplementary Figure S8). The highest molecular ion peak at $8448.21 \mathrm{~m} / z$ is very close to the molecular mass of the fully functionalized dendrimer $\left(8443.12 \mathrm{~g} \mathrm{~mol}^{-1}\right)$. The peaks at 8271.9 and $8092.4 \mathrm{~m} / z$ matched the molecular mass of the dendrimers missing 2 and 4 branches ( 8256.85 and $8070.58 \mathrm{~g} \mathrm{~mol}^{-1}$ ), respectively. The elemental analysis of POSS-Im32 also matched the dendrimer missing 4 branches, which was associated with $18 \mathrm{H}_{2} \mathrm{O}$ molecules. These observations agree well with the results on the degrees of functionalization of POSS-Im16 and POSS-Im32 obtained from ${ }^{1} \mathrm{H}$ NMR, as described above.

\section{$\mathrm{pH}$ response}

Sensitivities of dendrimer phase transitions to $\mathrm{pH}$ were evaluated by changes in transmittance intensity of the dendrimer solutions. The initial dendrimer solutions were prepared at $\mathrm{pH}=6.5$ with $0.1 \mathrm{M} \mathrm{HCl}$, and the solution $\mathrm{pH}$ values were adjusted by adding $0.1 \mathrm{M} \mathrm{NaOH}$ solution. POSS-Im16 with a concentration of $0.02 \mathrm{mmol}$ and POSSIm32 with a concentration of $0.01 \mathrm{mmol}$ corresponding to $0.32 \mathrm{mmol}$ of the imidazole unit were dissolved in $60 \mathrm{ml}$ of distilled water. Transmittance of the POSS-Im32 solution drastically decreased when the solution $\mathrm{pH}$ was $>7.2$ (Figure 2). This was attributed to the hydrophilic-to-hydrophobic transition arising from deprotonation of the imidazole groups. Figure 3 shows $\mathrm{pH}$ dependence of the

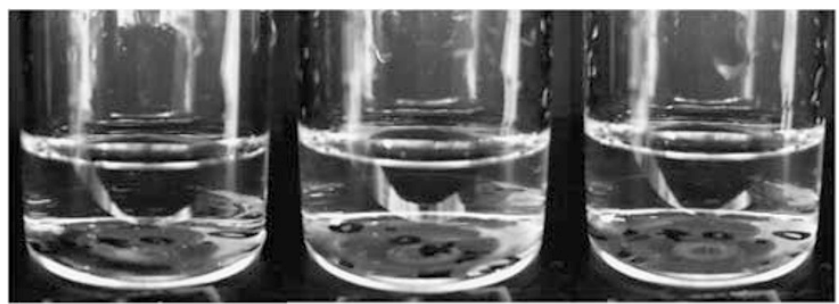

pH 6.40

pH 6.73

pH 6.92

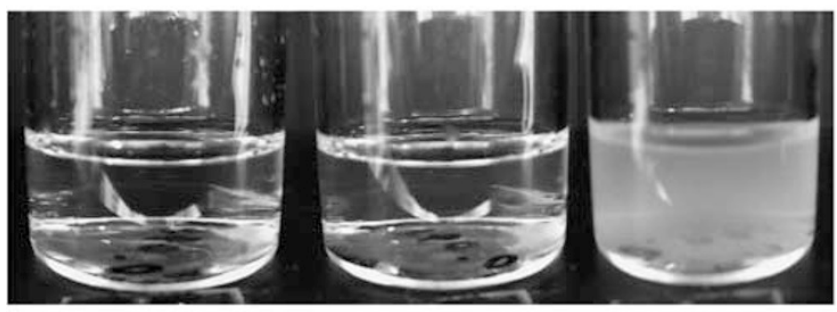

pH 7.09

pH 7.34

pH 7.49

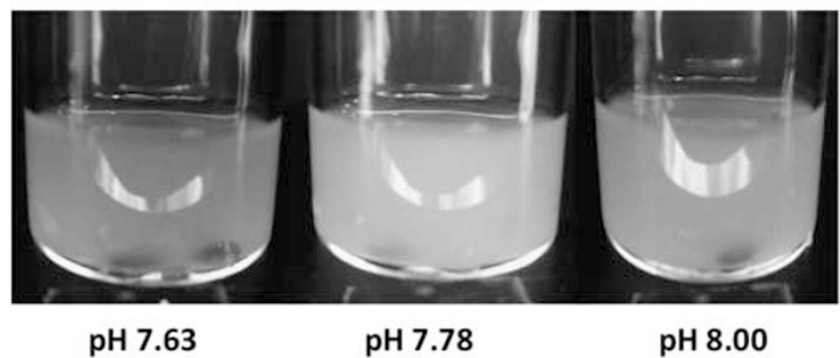

Figure 2 Photographs of POSS-Im32 solution $\left(0.17 \mathrm{mmol} \mathrm{I}^{-1}\right)$ with different $\mathrm{pH}$. POSS, poly(amidoamine)-type oligomeric silsesquioxane. A full color version of this figure is available at Polymer Journal online.

turbidity of the dendrimer solutions measured at a wavelength of $600 \mathrm{~nm}$. Transmittances of the dendrimer solutions reversibly changed with $\mathrm{pH}$ without hysteresis. However, in the case of POSS-Im16, the solution remained transparent in the range of the changing $\mathrm{pH}$. The turbidity point occurred beyond the $\mathrm{pH}$ of 8.0 as the amount of POSS-Im16 increased to $0.06 \mathrm{mmol}$. These results suggest that $\mathrm{pH}$ of the turbidity points decreased with increasing generation numbers.

The $\mathrm{pH}$ titration results of POSS-Im16, POSS-Im32 and 1-methylimidazole are shown in Figure 4. Although the dendrimers were polyelectrolytes, they had well-defined one-step titration curves similar to those of 1-methylimidazole, a monomeric imidazole compound. According to Figure 4, the pKa values of 1-methylimidazole, POSSIm16 and POSS-Im32 were 7.3, 7.0 and 6.7, respectively. These values decreased as the number of imidazole units per molecule increased, suggesting that deprotonation of the ammonium groups of the later generation is easier than that of the earlier generation. This is caused by electrostatic repulsions between the neighboring imidazole groups due to their close-packed structures. ${ }^{15}$ Crooks and colleagues ${ }^{16}$ reported that the slopes of titration curves of imidazole-terminated poly(propyleneimine) dendrimers did not have a sharp break, making it difficult to determine their $\mathrm{pKa}$. They further suggested that the imidazole groups on the surfaces of these dendrimers are communicating with one another and the branched groups. However, the 


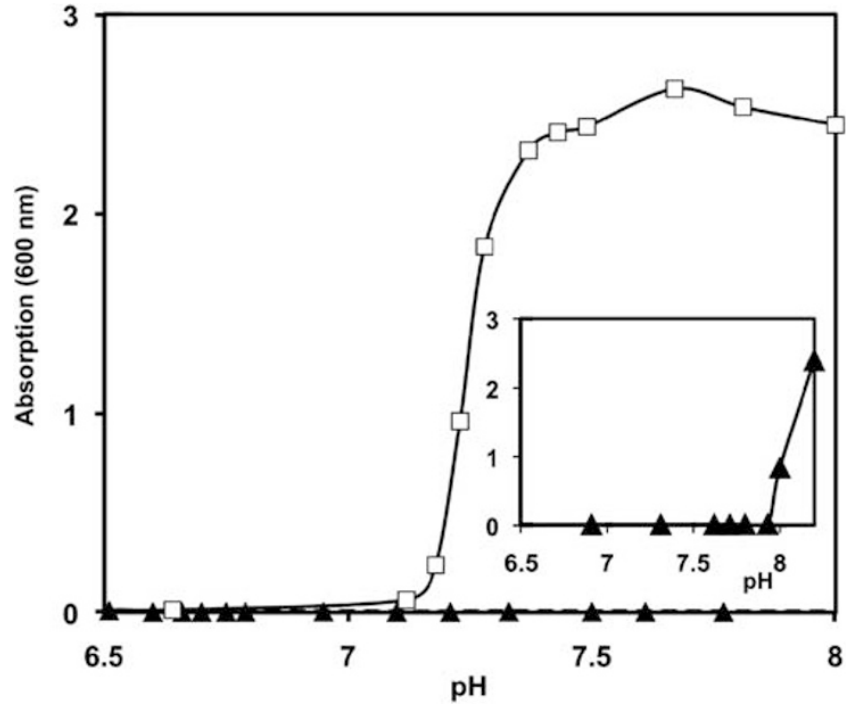

Figure 3 Dependence of the turbidity of the aqueous POSS-Im32 solutions $(0.01 \mathrm{mmol})(\square)$ and the POSS-Im16 solution $(0.02 \mathrm{mmol})(\boldsymbol{\Lambda})$ on $\mathrm{pH}$. The dendrimers are dissolved in $60 \mathrm{ml}$ of distilled water. The inset is the POSSIm16 dendrimer $(0.06 \mathrm{mmol})$ dissolved in $60 \mathrm{ml}$ of distilled water. POSS, poly(amidoamine)-type oligomeric silsesquioxane.

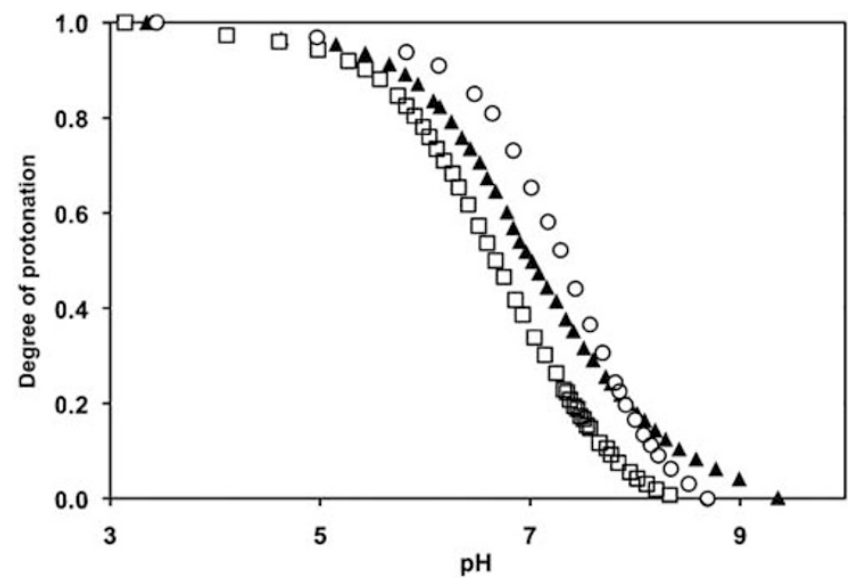

Figure 4 Potentiometric titrations of 1-methylimidazole $(O)$, POSS-Im16 $(\mathbf{\Lambda})$ and POSS-Im32 ( $\square$ ) in $2.0 \mathrm{~m} \mathrm{NaCl}$ solution with $0.1 \mathrm{~m} \mathrm{NaOH}$ solution. The imidaozole unit of the samples is constant at $0.32 \mathrm{mmol}$. POSS, poly(amidoamine)-type oligomeric silsesquioxane.

present POSS-core dendrimers had well-defined one-step titration curves. The protonation amount matched the total protonation amount of the surfaces and the branched amines, suggesting that the terminal imidazole groups and the branched amines are isolated; in addition, they inhibited the association of neighboring branches due to the POSS-core structures. Such simple acid-base behavior provides the sharp response to $\mathrm{pH}$ shown in Figure 3. The degrees of protonation at the turbidity points for POSS-Im16 and POSS-Im32 are 0.19 and 0.28 , respectively. These results indicate that increasing the generation number promotes aggregation in an aqueous solution at lower $\mathrm{pH}$ values with a higher degree of protonation.

\section{Coordination behavior}

The complexing behaviors of POSS-Im16 and POSS-Im32 with $\mathrm{Cu}^{2+}$ ions were studied. The coordination geometry of $\mathrm{Cu}^{2+}$ complexation systems is expected at the position of maximum absorption of the $d-d$ transition. ${ }^{17-21} \mathrm{~A} \mathrm{Cu}^{2+}-\mathrm{N}_{4}$ complex involving four tertiary amine groups or amide nitrogens is a possible type of complex when maximum absorption of the $\mathrm{d}-\mathrm{d}$ transition is observed at $\sim 600 \mathrm{~nm}$. A Cu${ }^{2+}-\mathrm{N}_{2} \mathrm{O}_{2}$ complex involving two oxygen groups and two tertiary amine groups is a possible type of complex when the absorption maximum of the $\mathrm{d}-\mathrm{d}$ transition is $>650 \mathrm{~nm}$. Earlier studies that reported the $\mathrm{d}-\mathrm{d}$ transition $\sim 700 \mathrm{~nm}$ indicated that the ligand is coordinated with two tertiary nitrogen atoms and two amide oxygen atoms in the equatorial plane and that one amide oxygen atom is axially coordinated. ${ }^{22}$ To examine the coordination modes of the dendrimers with $\mathrm{Cu}^{2+}$ ions, we performed spectrophotometric titration and kept the amount of $\mathrm{Cu}^{2+}$ ions titrated into the solutions at $0.2 \mathrm{~mm}$ for POSS-Im16 and $0.1 \mathrm{~mm}$ for POSS-Im32. When the concentration ratio between POSS-Im16 and the $\mathrm{Cu}^{2+}$ ions decreased, the positions of the absorption maxima shifted gradually from $604 \mathrm{~nm}$ to a longer wavelength at $763 \mathrm{~nm}$ (Figure 5a). The shift in the absorption maxima with decreasing dendrimer amounts indicates that the coordination modes of POSS-Im16 shifted from the $\mathrm{Cu}^{2+}$ $\mathrm{N}_{4}$ complex to the $\mathrm{Cu}^{2+}-\mathrm{N}_{2} \mathrm{O}_{2}$ complex through intermediate coordination states. ${ }^{19}$ On the other hand, the absorption maxima remained at $600 \mathrm{~nm}$ regardless of the $\mathrm{Cu}^{2+}$ ion and POSS-Im32 concentration (Figure 5b). When the dendrimer concentration was low, that is, [imidazole $] /\left[\mathrm{Cu}^{2+}\right]=1.6$ and 0.8 , the absorption peak had a maximum at $600 \mathrm{~nm}$ with an additional shoulder at $\sim 800 \mathrm{~nm}$. This indicates that only the $\mathrm{Cu}^{2+}-\mathrm{N}_{4}$ complexation mode exists between $\mathrm{Cu}^{2+}$ ions and POSS-Im32.

Figure 6 shows the spectrophotometric titration plots. The POSSIm16 and POSS-Im32 samples were measured spectrophotometrically at the absorption wavelength of $604 \mathrm{~nm}$. The absorption intensities increased as the concentration ratios between POSS-Im16 and $\mathrm{Cu}^{2+}$ ions increased up to a value of 0.25 ; similarly, the absorption intensity increased with the concentration ratio between POSS-Im32 and the $\mathrm{Cu}^{2+}$ ions up to a ratio of 0.20 . The data indicate that the binding capacities of $\mathrm{Cu}^{2+}$ to POSS-Im16 and POSS-Im32 were approximately four and five $\mathrm{Cu}^{2+}$ ions, respectively. Additional studies using the more precise continuous variation method were performed to confirm the binding capacities $\mathrm{Cu}^{2+}$ to the dendrimers (Figure 7 and Supplementary Figure S9). Solutions containing $\mathrm{Cu}^{2+}$ ions and dendrimers in varying concentrations were prepared, and the total reagent concentration $\left(\left[\mathrm{Cu}^{2+}\right]+[\right.$ dendrimer $\left.]\right)$ was maintained at $0.5 \mathrm{~mm}$ for the solution with either POSS-Im16 or POSS-Im32. The absorbance of each $\mathrm{Cu}^{2+}$-dendrimer solution was plotted against the molar ratio between the dendrimer and the total concentration of the reagent. The absorptions at $604 \mathrm{~nm}$ for POSS-Im16 and POSS-Im32 were used for the Job plots. The Job plot at a longer absorption wavelength of $763 \mathrm{~nm}$ for POSS-Im16 was also drawn. The data for POSS-Im16 in Figure 7 show that the inflection points $(X)$ of the Job plots were observed at $X=0.15$ for $763 \mathrm{~nm}$ and at $X=0.20$ for $604 \mathrm{~nm}$ (Table 1), indicating the presence of complexes with 5.7 and $4.0 \mathrm{Cu}^{2+}$ ions, respectively. Although 16 imidazole nitrogens on the surface and 8 tertiary amines in the branch can potentially coordinate with $\mathrm{Cu}^{2+}$ ions, the present data suggest that the amine units in POSS-Im16 rarely formed $\mathrm{Cu}^{2+}-\mathrm{N}_{2} \mathrm{O}_{2}$ and $\mathrm{Cu}^{2+}-\mathrm{N}_{4}$ complexes because the movement of the terminal groups and branch units was suppressed. Using the inflection points on the plots for the $\mathrm{Cu}^{2+}-\mathrm{N}_{2} \mathrm{O}_{2}$ and $\mathrm{Cu}^{2+}-\mathrm{N}_{4}$ complexes, it was calculated that 2.8 and 4.0 terminal imidazole units coordinated with one $\mathrm{Cu}^{2+}$ ion. According to these data, the dendrimer likely coordinated with most of $\mathrm{Cu}^{2+}$ ions at their imidazole nitrogen, and no tertiary amines in the branches were used for coordination because the interior amines were sterically 

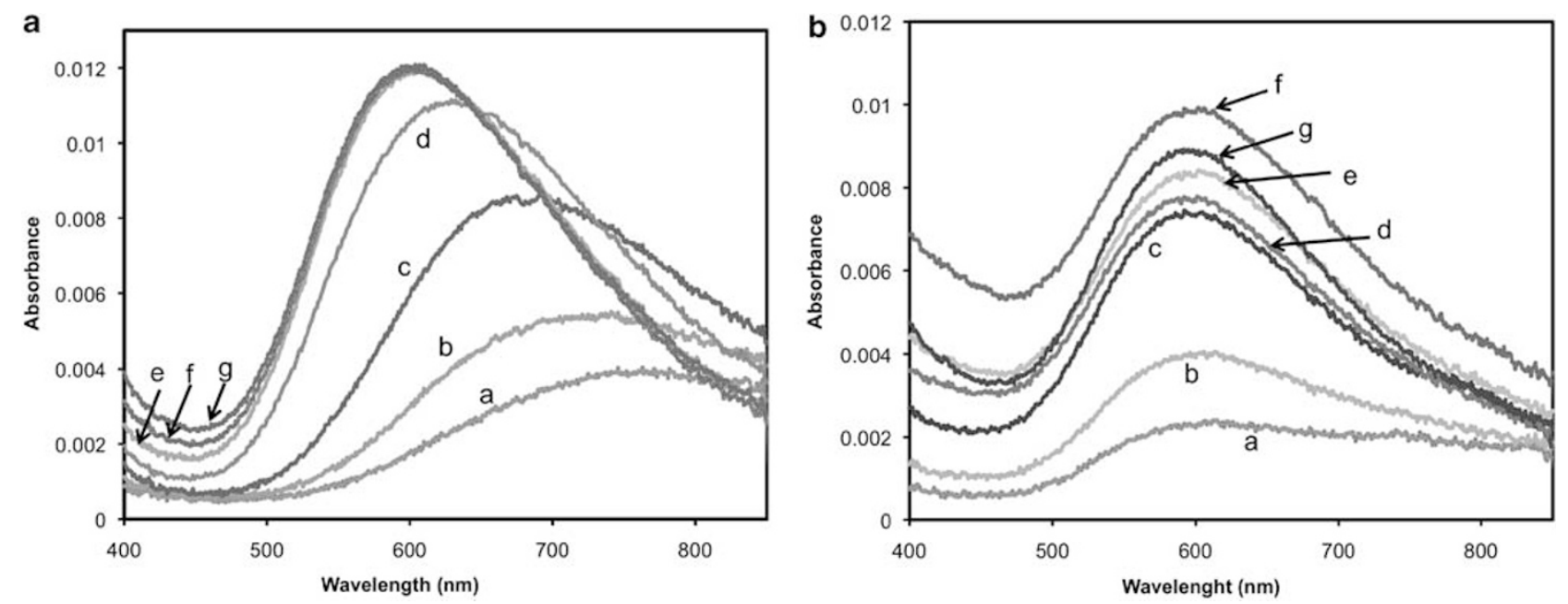

Figure 5 Spectrophotometric titrations of (a) POSS-Im16 and (b) POSS-Im32 against the $\mathrm{Cu}^{2+}$ ions. The amount of $\mathrm{Cu}^{2+}$ ions titrated into the solutions is $0.2 \mathrm{~mm}$ for POSS-Im16 and $0.1 \mathrm{~mm}$ for POSS-Im32. [dendrimer] $/\left[\mathrm{Cu}^{2+}\right]=$ (a) 0.025, (b) 0.05, (c) 0.125, (d) 0.25, (e) 0.50, (f) 0.75, and (g) 1.00. A full color version of this figure is available at Polymer Journal online.

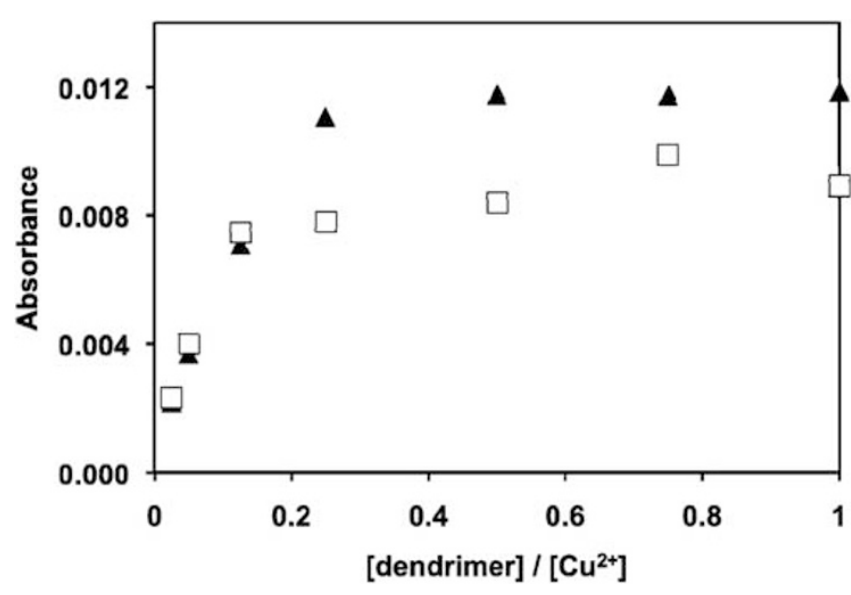

Figure 6 Spectrophotometric titration plots: absorption at $604 \mathrm{~nm}$ as a function of the number of POSS-Im16 $(\mathbf{\Lambda})$ and POSS-Im32 $(\square)$ molecules per $\mathrm{Cu}^{2+}$ ions. The concentration of $\mathrm{Cu}^{2+}$ ions is maintained at $0.2 \mathrm{~mm}$ for POSS-Im16 and $0.1 \mathrm{~mm}$ for POSS-Im32. POSS, poly(amidoamine)-type oligomeric silsesquioxane.

hindered. For POSS-Im32, the inflection point at the maximum absorbance was 0.15 , indicating that $5.7 \mathrm{Cu}^{2+}$ ions coordinated with one dendrimer and 5.6 terminal imidazole units coordinated with one $\mathrm{Cu}^{2+}$ ion.

\section{CONCLUSIONS}

We have successfully synthesized imidazole-terminated first- and second-generation poly(amidoamine)-type POSS-core dendrimers. The results of $\mathrm{pH}$ titrations for POSS-Im16 and POSS-Im32 showed well-defined one-step titration curves identical to the curves of monomeric imidazole compounds, such as 1-methylimidazole. The terminal functional groups on the POSS-core dendrimers showed chemical behaviors similar to those of the corresponding monomeric molecules in the solution. This suggests that the terminal functional groups are isolated, and they inhibit the movement of neighboring branches. Such simple acid-base behavior caused dendrimer phase

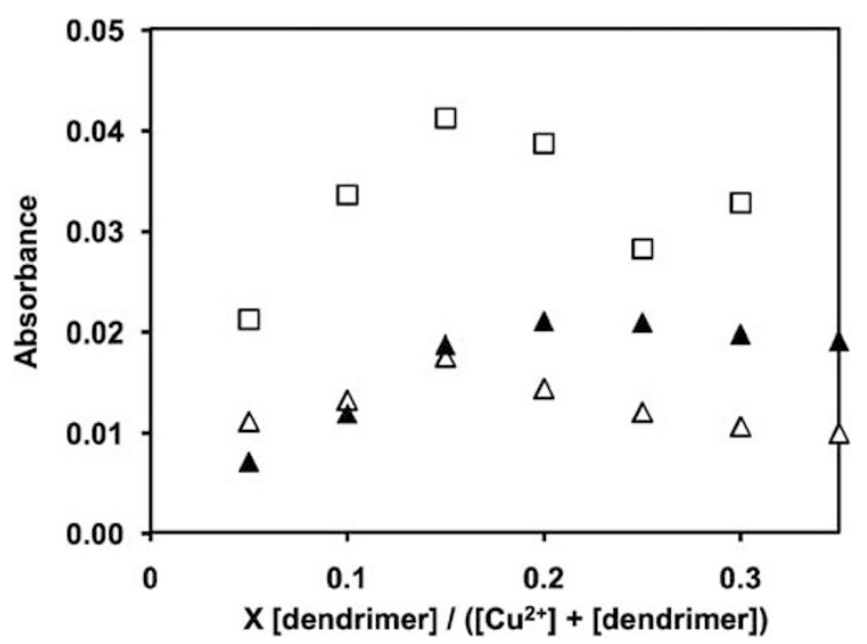

Figure $7 \mathrm{Job}$ plots between the dendrimers and $\mathrm{CuSO}_{4} \cdot\left[\mathrm{Cu}^{2+}\right]+$ [dendrimer] is $0.5 \mathrm{~mm}$ for POSS-Im16 ( $\mathbf{\Delta}: 604 \mathrm{~nm} ; \triangle: 763 \mathrm{~nm})$ and $0.5 \mathrm{~mm}$ for POSS-Im32 ( $\square: 604 \mathrm{~nm}$ ). POSS, poly(amidoamine)-type oligomeric silsesquioxane.

Table 1 The $\mathrm{Cu}^{2+-t o-l i g a n d ~ s t o i c h i o m e t r y ~ f r o m ~ t h e ~ J o b ~ p l o t s ~ a s ~}$ shown in Figure ${ }^{a}$

\begin{tabular}{|c|c|c|c|}
\hline Dendrimer & Wavelength $(n m)^{b}$ & {$\left[\mathrm{Cu}^{2+}\right] /[$ dendrimer $]$} & {$\left[\right.$ imidazole]/[C $\left.\mathrm{Cu}^{2+}\right]$} \\
\hline POSS-Im16 & 763 & 5.7 & 2.8 \\
\hline POSS-Im 16 & 604 & 4.0 & 4.0 \\
\hline POSS-Im32 & 604 & 5.7 & 5.6 \\
\hline
\end{tabular}

Abbreviation: POSS, poly(amidoamine)-type oligomeric silsesquioxane

${ }^{a}$ Total reagent concentration $\left(\left[\mathrm{Cu}^{2+}\right]+[\right.$ dendrimer] $)$ is $0.5 \mathrm{~mm}$.

${ }^{b}$ The absorption wavelength of the d-d transition of $\mathrm{Cu}^{2+}$ for the Job's plots.

${ }^{\mathrm{c}} \mathrm{On}$ the basis of the numbers of the outermost tertiary amines. 
transitions to be highly sensitive to $\mathrm{pH}$ changes. The $\mathrm{pKa}$ values of 1methylimidazole, POSS-Im16 and POSS-Im32 were 7.3, 7.0 and 6.7, respectively. These values decreased with increasing generation numbers, suggesting that deprotonation of the imidazolium and ammonium groups is easier in the later generation than in the earlier generations because of the electrostatic repulsions between the neighboring imidazole groups caused by their close-packed structures. According to the spectrophotometric study, we found that coordination modes of POSS-Im16 changed from the $\mathrm{Cu}^{2+}-\mathrm{N}_{2} \mathrm{O}_{2}$ complex to the $\mathrm{Cu}^{2+}-\mathrm{N}_{4}$ complex as concentrations of the dendrimer increased; in addition, only one complexation mode $\left(\mathrm{Cu}^{2+}-\mathrm{N}_{4}\right)$ existed between $\mathrm{Cu}^{2+}$ ions and POSS-Im32. These results suggest that the terminal functional groups in the first-generation POSS-core dendrimer are isolated and inhibit the movement and association of neighboring branches; the functional groups in the second-generation dendrimers are closely positioned on the external surfaces due to fewer entangled branches. These characteristics of the POSS-core dendrimers could provide unique functions that conventional dendrimers could not. Further studies to reveal additional characteristics of the POSS-core dendrimers are underway.

\section{CONFLICT OF INTEREST}

The authors declare no conflict of interest.

\section{ACKNOWLEDGEMENTS}

This study is a part of the Kyoto City Collaboration of Regional Entities for the Advancement of Technology Excellence of JST. We thank Professor Tsuyoshi Kawai of the Nara Institute of Science and Technology for making MALDITOF-MS measurements, which are supported by the Kyoto-Advance Nanotechnology Network.

1 Feher, F. J. \& Wyndham, K. D. Amine and ester-substituted silsesquioxanes: synthesis, characterization and use as a core for starburst dendrimers. Chem. Commun. 34, 323324 (1998)

2 Feher, F. J., Wyndham, K. D., Soulivong, D. \& Nguyen, F. Syntheses of highly functionalized cube-octameric polyhedral oligosilsesquioxanes (R8Si8012). J. Chem. Soc. Dalton Trans. 28, 1491-1497 (1999).

3 Jaffrés, P.- A. \& Morris, R. E. Synthesis of highly functionalized dendrimers based on polyhedral silsesquioxane cores. J. Chem. Soc. Dalton Trans. 27, 2767-2770 (1998).

4 Zhang, X., Haxton, K. J., Ropartz, L., Cole-Hamilton, D. J. \& Morris, R. E. Synthesis and computer modeling of hydroxy-derivatised carbosilane dendrimers based on polyhedral silsesquioxane cores. J. Chem. Soc. Dalton Trans. 30, 3261-3268 (2001).
5 Haxton, K. J., Cole-Hamilton, D. J. \& Morris, R. E. Silsesquioxane dendrimers as catalysts: a bite-sized molecular dynamics study. Dalton Trans. 36, 3415-3420 (2007).

6 Naka, K., Fujita, M., Tanaka, K. \& Chujo, Y. Water-soluble anionic POSS-core dendrimer: synthesis and copper (II) complexes in aqueous solution. Langmuir 23, 9057-9063 (2007).

7 Tanaka, K., Inafuku, K., Naka, K. \& Chujo, Y. Enhancement of entrapping ability of dendrimers by a cubic silsesquioxane core. Org. Biomol. Chem. 6, 3899-3901 (2008).

8 Haba, Y., Harada, A., Takagishi, T. \& Kono, K. Rendering poly(amidoamine) or poly(propylenimine) dendrimers temperature sensitive. J. Am. Chem. Soc. 126, 12760-12761 (2004).

9 Haba, Y., Kojima, C., Harada, A. \& Kono, K. Control of temperature-sensitive properties of poly(amidoamine) dendrimers using peripheral modification with various alkylamide groups. Macromolecules 39, 7451-7453 (2006).

10 You, Y. Z., Hong, C. Y., Pan, C. Y. \& Wang, P. H. Synthesis of a dendritic coreshell nanostructure with a temperature-sensitive shell. Adv. Mater. 16, 1953-1957 (2004).

11 Li, W., Zhang, A., Chen, Y., Feldman, K., Wu, H. \& Schlüter, A. D. Low toxic, thermoresponsive dendrimers based on oligoethylene glycols with sharp and fully reversible phase transitions. Chem. Commun. 44, 5948-5950 (2008).

12 Soler-Padrós, J., Pérez-Mayoral, E., Domínguez, L., López-Larrubia, P., Soriano, E., Marco-Contelles, J. L., Cerdán, S. \& Ballesteros, P. Novel generation of pH indicators for proton magnetic resonance spectroscopic imaging. J. Med. Chem. 50, 4539-4542 (2007).

$13 \mathrm{Seo}, \mathrm{K}$. \& Kim, D. Phase transition behavior of novel pH-sensitive polyaspartamide derivatives grafted with 1-(3-aminopropyl)imidazole. Macromol. Biosci. 6, 758-766 (2006).

14 Park, H. W., Jin, H.- S., Yang, S. Y. \& Kim, J.- D. Tunable phase transition behaviors of $\mathrm{pH}$-sensitive polyaspartamides having various cationic pendant groups. Colloid Polym. Sci. 287, 919-926 (2009).

15 Naka, K., Kobayashi, A. \& Chujo, Y. Effect of anionic 4.5-generation polyamidoamine dendrimer on the formation of calcium carbonate polymorphs. Bull. Chem. Soc. Jpn 75, 2541-2546 (2002).

16 Baker, L. A., Sun, L. \& Crooks, R. M. Synthesis and catalytic properties of imidazolefunctionalized poly(propylene imine) dendrimers. Bull. Korean Chem. Soc. 23, 647-654 (2002).

17 Ojima, H. \& Sone, K. Absorption spectra and catalytic behavior of the copper(II) chelates of some alkylated ethylenediamines. Bull. Chem. Soc. Jpn 35, 298-303 (1962).

18 Jonassen, H. B. \& Dexter, T. H. Inorganic complex compounds containing polydentate groups. I. The complex ions formed between copper(II) ions and ethylenediamine. J. Am. Chem. Soc. 71, 1553-1556 (1949).

19 Edsall, J. D., Felsenfeld, G., Goodman, D. S. \& Gurd, F. R. N. The association of imidazole with the ions of zinc and cupric copper. J. Am. Chem. Soc. 76, 3054-3061 (1953).

20 Jonassen, H. B., Reeves, R. E. \& Segal, L. Inorganic complex compounds containing polydentate groups. XI. Effect of hydroxide ion on the bis-ethylenediaminecopper(II) ion. J. Am. Chem. Soc. 77, 2748-2749 (1955).

21 Billo, E. J. Copper(II) chromosomes and the rule of average environment. Inorg. Nucl. Chem. Lett. 10, 613-617 (1974).

22 Krot, K. A. Namor, A. F. D. Aguilar-Cornejo, A. \& Nolan, K. B. Speciation, stability constants and structures of complexes of copper(II), nickel(II), silver(I) and mercury(II) with PAMAM dendrimer and related tetraamide ligands. Inorg. Chim. Acta 358, 3497-3505 (2005).

Supplementary Information accompanies the paper on Polymer Journal website (http://www.nature.com/pj) 